\title{
Direct capture of carbon dioxide from air via lime-based sorbents
}

\author{
Mohammad Samari $^{1} \cdot$ Firas Ridha $^{2}$ - Vasilije Manovic ${ }^{3} \cdot$ Arturo Macchi $^{1}$ • \\ E. J. Anthony ${ }^{3}$ (D)
}

Received: 22 June 2018 / Accepted: 21 January 2019 / Published online: 21 February 2019

(C) The Author(s) 2019

\begin{abstract}
Direct air capture (DAC) is a developing technology for removing carbon dioxide $\left(\mathrm{CO}_{2}\right)$ from the atmosphere or from low- $\mathrm{CO}_{2}$-containing sources. In principle, it could be used to remove sufficient $\mathrm{CO}_{2}$ from the atmosphere to compensate for hard-to-decarbonize sectors, such as aviation, or even for polishing gas streams containing relatively low $\mathrm{CO}_{2}$ concentrations. In this paper, the performance of lime-based sorbents for $\mathrm{CO}_{2}$ capture from air in a fixed bed was investigated. The effects of sorbent type, particle diameter, air flow rate, and relative humidity on the breakthrough time, breakthrough shape, and global reaction rate over a series of capture and regeneration cycles were examined. The greatest reaction rates and conversions were obtained when the sorbents were pre-hydrated and inlet air was humidified to $55 \%$ relative humidity. Humidifying the air alone leads to axial carbonation gradients since there is competition between $\mathrm{CO}_{2}$ and water with the available $\mathrm{CaO}$. Negligible conversion, over the duration of the experiment, is obtained in a dry system without pre-hydration and humid air. A shrinking-core gas-solid reaction model was fitted to the breakthrough curves in order to estimate the surface reaction and effective diffusion constants. Although the surface reaction constants of the two sorbents were similar, the pelletized limestone had a greater effective diffusivity due to its greater porosity. At mild calcination conditions with air at $850{ }^{\circ} \mathrm{C}$, the pelletized particles maintained their activity over nine carbonation-calcination cycles with a conversion drop of only $9 \%$ points. However, calcination under oxy-fuel conditions $\left(\mathrm{CO}_{2}\right.$ at $920{ }^{\circ} \mathrm{C}$ ) reduced the pellet carbonation conversion from 81 to $59 \%$ and pore surface area from 12.01 to $3.20 \mathrm{~m}^{2} / \mathrm{g}$ after only 4 cycles. This research clearly shows that DAC using lime-based
\end{abstract}

Electronic supplementary material The online version of this article (https://doi.org/10.1007/s11027-0199845-0) contains supplementary material, which is available to authorized users.

\section{E. J. Anthony}

b.j.anthony@cranfield.ac.uk

1 Centre for Catalysis Research and Innovation, Department of Chemical and Biological Engineering, University of Ottawa, Ottawa K1N 6N5, Canada

2 CanmetENERGY, 1 Haanel Drive, Ottawa K1A 1M1, Canada

3 Centre for Climate and Environmental Protection, Cranfield University, Cranfield, Bedfordshire, UK 
sorbents is technically feasible, and that regeneration schemes compatible with technologies like calcium looping $(\mathrm{CaL})$ are applicable for the air capture option. Finally, this study demonstrates that DAC using lime-based materials can be in the future a strategy to address emissions from transportation and distributed $\mathrm{CO}_{2}$ sources and to mitigate climate change.

Keywords Climate change $\cdot$ Direct air capture $\cdot$ Limestone $\cdot$ Calcination $\cdot$ Carbonation

\section{Introduction}

It is clear that anthropogenic emission of greenhouse gases (GHGs) is causing significant climate change (IPCC 2007; Lüthi et al. 2008; Petit et al. 1999). According to the 2010 annual report of the International Energy Agency (IEA), two thirds of the global carbon dioxide $\left(\mathrm{CO}_{2}\right)$ emissions are from the electricity/heat generation and transport sectors (IEA 2011). Since fossil fuels are still the least expensive source of energy, it is predicted that GHG emissions due to combustion of fossil fuels (e.g., coal, oil, and natural gas) will rise by $25-90 \%$ between 2000 and 2030 (Ranjan and Herzog 2011). Carbon capture and storage (CCS) is the process of capturing $\mathrm{CO}_{2}$ from large point sources and producing a concentrated and pressurized stream of $\mathrm{CO}_{2}$ for storage. However, about $60 \%$ of $\mathrm{CO}_{2}$ emissions is attributed to dilute, distributed sources (IEA 2013) and while oceans absorb much of the emitted $\mathrm{CO}_{2}, 20-40 \%$ of it remains in the atmosphere (Bottoms 1930).

Direct air capture (DAC) is a developing, flexible technology for removing $\mathrm{CO}_{2}$ from the atmosphere that can, in principle, be built anywhere. Unlike other $\mathrm{CO}_{2}$ removal processes, it does not require a relatively concentrated source of $\mathrm{CO}_{2}$ such as provided by flue gas or process streams from carbon-intensive industries. The most important benefit of DAC is to remove sufficient $\mathrm{CO}_{2}$ from the environment, to compensate for otherwise difficult-to-decarbonize sectors such as aviation or transportation. Given that DAC is always going to be more expensive than decarbonizing concentrated gas streams from fossil fuel conversion, its most likely applications are either to polish dilute gas streams (residual $\mathrm{CO}_{2}$ from CCS processes) or as a method to compensate for the use of fossil fuels in transportation options.

Capturing $\mathrm{CO}_{2}$ with a partial pressure $p_{0}$ from a mixture of gases and separating it as a concentrated $\mathrm{CO}_{2}$ stream with a pressure $P$, needs $k \operatorname{Tn}\left(P / P_{0}\right)$ energy, where $k$ and $T$ are the Boltzman constant and working temperature, respectively. Therefore, capturing $\mathrm{CO}_{2}$ (partial pressure $\sim 4 \times 10^{-4}$ bar) from air and compressing it to 101.3 bar, which is required for sequestration, needs an energy input of almost $4 \mathrm{GJ} / \mathrm{t}$ carbon. Comparing this value with the carbon-specific energy content of fossil fuels, such as coal, oil, and natural gas (40-70 GJ/t carbon), suggests that part of the energy from carbon fuels could be used for $\mathrm{CO}_{2}$ capture rather than the $\mathrm{CO}_{2}$ being emitted to the atmosphere (Keith et al. 2006). The environmental advantages of $\mathrm{CO}_{2}$ capture from air are undeniable. For instance, $\mathrm{CO}_{2}$ capture plants could be constructed near the final storage sites, in locations where land is cheap, and energy for the separation process could be obtained from renewable sources (e.g., wind or solar) and, additionally, transportation costs are marginal. DAC could also be used for the tailing $\mathrm{CO}_{2}$ treatment of power generation plants or oil and gas refineries, where $100 \% \mathrm{CO}_{2}$ capture is not normally achieved (Nikulshina et al. 2006).

One method for DAC using hydroxide solutions has been explored by Carbon Engineering Ltd. in Canada (Carbon Engineering 2019). The process consists of two main cycles: an air 
contactor $\left(\mathrm{CO}_{2}\right.$ capture cycle $)$ and a sorbent regeneration cycle. In the first cycle, $\mathrm{CO}_{2}$ from air is absorbed by means of a chemical solution to form a carbonate (e.g., $\mathrm{K}_{2} \mathrm{CO}_{3}$ ). The carbonate solution then reacts with calcium hydroxide $\left(\mathrm{Ca}(\mathrm{OH})_{2}\right)$ to form calcium carbonate $\left(\mathrm{CaCO}_{3}\right)$. In the next cycle, the $\mathrm{CaCO}_{3}$ is separated from solution and calcined to lime $(\mathrm{CaO})$ in an oxyfired fluidized bed that operates at approximately $900{ }^{\circ} \mathrm{C}$. During this stage, $\mathrm{CO}_{2}$ is released while the $\mathrm{CaO}$ is recycled and rehydrated to $\mathrm{Ca}(\mathrm{OH})_{2}$. Finally, this hydroxide is used to react with the carbonate solution (Mahmoudkhani and Keith 2009). However, since the process uses a solution, good contact between the liquid and ambient air is critical when a spray-based system and a packed tower are employed (Mahmoudkhani et al. 2009). Furthermore, these methods have some drawbacks, due to the high cost of sorbent regeneration, solvent losses, and the presence of alkali metal salt impurities in any calcium loop that enhances sintering and loss of sorption capacity. Therefore, eliminating the use of alkali metal hydroxides altogether and using lime-based sorbents is inherently simpler, and takes advantage of the fact that lime is, after water, arguably the cheapest and most commonly available industrial chemical, and has numerous uses, including as will be discussed below, in the cement and steel industries.

By contrast, amine-based scrubbing is a mature technology that has been used for more than 80 years in the oil and gas industry for acid gas $\left(\mathrm{H}_{2} \mathrm{~S}\right.$ and $\left.\mathrm{CO}_{2}\right)$ removal (Astarita et al. 1993). However, for DAC, solutions such as diethanolamine (DEA) and monoethanolamine (MEA) are unsuitable since their $\mathrm{CO}_{2}$ capture capacity drops drastically at low $\mathrm{CO}_{2}$ partial pressures. Therefore, amine-based solid sorbents have been proposed instead. Supported amine adsorbents are classified into two categories. In class 1 adsorbents, amine molecules are loaded into polymeric or silica supports. These amine molecules are physisorbed on the surface and in the pores of the support. For class 2 adsorbents, amine molecules are bound to the surface of the support by covalent bonds. Studies show that class 2 adsorbents have better performance than other adsorbents such as zeolites and mesoporous silica at low $\mathrm{CO}_{2}$ partial pressure (Choi et al. 2011). Despite the relatively low regeneration energy requirement of amine-based sorbents, their relatively high costs, poor $\mathrm{CO}_{2}$ capture capacity from air, and degradation are issues that make them less attractive options (Choi et al. 2011; Sculley and Zhou 2012).

Finally, $\mathrm{CO}_{2}$ capture at high temperature via new lime-based sorbents, which are enhanced with calcium aluminate cement binders and pelletized, has been investigated by CanmetENERGY-Ottawa. Thermogravimetric analyzer (TGA) results show improved sorption capacity relative to natural limestone (Manovic and Anthony 2009a, 2010; Manovic et al. 2012) due to the formation of mayenite $\left(\mathrm{Ca}_{12} \mathrm{Al}_{14} \mathrm{O}_{33}\right)$, which reduces sintering during $\mathrm{CO}_{2}$ capture cycles (Manovic and Anthony 2009a, b, 2010; Manovic et al. 2012).

Limestone is extensively used in the cement industry as a source of $\mathrm{CaO}$ and is responsible for 7-10\% of anthropogenic $\mathrm{CO}_{2}$ emissions (Zheng et al. 2016). Calcium looping (CaL) has been proposed as an option for the cement industry to capture $\mathrm{CO}_{2}$ (Erans et al. 2018). Here, the $\mathrm{CaO}$ from $\mathrm{CaL}$ can be used in DAC, or if DAC is carried out with a lime-based sorbent, then the spent lime can be fed back into the cement industry. Recently, it has also been demonstrated that lime can be very efficiently used in the steel industry for decarbonization as well, using a variant of the $\mathrm{CaL}$ option (Tian et al. 2018). The basic philosophy of this work is that limestone and lime-based materials are ubiquitous, cheap, nontoxic and are compatible with two of the most important industrial sources of anthropogenic $\mathrm{CO}_{2}$ (namely cement and steel), and a lime-based process, if it can be made to perform at a comparable level to DAC processes using sodium or potassium hydroxide, is inherently preferable. Thus, while to date, experiments on capturing $\mathrm{CO}_{2}$ focused on concentrations relevant to coal flue gases (10-15\%) at elevated temperatures (Zheng et al. 2016; Erans et al. 2018), here we seek to demonstrate that these sorbents are suitable for DAC. 
Significant carbonation of calcium hydroxide at ambient temperature can be achieved when the relative humidity (RH) of air is above $40 \%$ (Beruto and Botter 2000). Dheilly et al. (2002) suggest that the $\mathrm{H}_{2} \mathrm{O}$ rather than $\mathrm{CO}_{2}$ partial pressure dominates the carbonation reaction at low temperature. Furthermore, Yang et al. (2003) observed via atomic force microscopy (AFM) that the carbonation of calcium hydroxide at ambient conditions occurs when nano-droplets of water are formed on the surface of $\mathrm{Ca}(\mathrm{OH})_{2}$. The carbonation of lime at low temperature can then be said to occur in several steps (Kalinkin et al. 2005). First, gaseous $\mathrm{CO}_{2}$ dissolves in the water droplets and forms $\mathrm{H}_{2} \mathrm{CO}_{3}$ (Eq. 1) and then calcium hydroxide from the surface of the sorbent also dissolves in the water droplets. Here, $\mathrm{H}_{2} \mathrm{CO}_{3}$ dissociates to $\mathrm{H}^{+}, \mathrm{HCO}_{3}{ }^{-}$, and $\mathrm{CO}_{3}{ }^{2-}$ ions (Eqs. 2 and 3 ), and $\mathrm{Ca}(\mathrm{OH})_{2}$ to $\mathrm{Ca}^{2+}$ and $\mathrm{OH}^{-}$ions in solution (Eq. 4).

$$
\begin{gathered}
\mathrm{CO}_{2(\mathrm{~g})}+\mathrm{H}_{2} \mathrm{O}_{(\mathrm{l})} \leftrightarrow \mathrm{H}_{2} \mathrm{CO}_{3(\mathrm{aq})} \\
\mathrm{H}_{2} \mathrm{CO}_{3(\mathrm{aq})} \leftrightarrow \mathrm{HCO}_{3}{ }_{(\mathrm{aq})}+\mathrm{H}^{+}{ }_{(\mathrm{aq})} \\
\mathrm{HCO}_{3}{ }_{(\mathrm{aq})}^{-} \leftrightarrow \mathrm{CO}_{3}{ }^{2-}{ }_{(\mathrm{aq})}+\mathrm{H}^{+}{ }_{(\mathrm{aq})} \\
\mathrm{Ca}(\mathrm{OH})_{2(\mathrm{~s})} \leftrightarrow \mathrm{Ca}^{2+}{ }_{(\mathrm{aq})}+2 \mathrm{OH}_{(\mathrm{aq})}^{-}
\end{gathered}
$$

The overall carbonation reaction of $\mathrm{Ca}(\mathrm{OH})_{2}$ can then be written as follows:

$$
\mathrm{Ca}(\mathrm{OH})_{2}+\mathrm{CO}_{2} \leftrightarrow \mathrm{CaCO}_{3}+\mathrm{H}_{2} \mathrm{O}
$$

The formation of $\mathrm{CaCO}_{3}$ on the surface of $\mathrm{Ca}(\mathrm{OH})_{2}$ impedes diffusion of $\mathrm{CO}_{2}$. However, studies show high carbonation conversion of $\mathrm{Ca}(\mathrm{OH})_{2}$ is possible at ambient conditions and, therefore, it can be concluded that the new solid phase on the surface of the sorbent particle is non-protective (Nakicenovic et al. 2000). This can be explained by the formation of calcium bicarbonate $\left(\mathrm{Ca}\left(\mathrm{HCO}_{3}\right)_{2}\right)$, (Pontiga et al. 2013):

$$
\mathrm{CaCO}_{3}+\mathrm{CO}_{2}+\mathrm{H}_{2} \mathrm{O} \rightarrow \mathrm{Ca}\left(\mathrm{HCO}_{3}\right)_{2}
$$

The higher solubility of $\mathrm{Ca}\left(\mathrm{HCO}_{3}\right)_{2}$ enhances $\mathrm{CO}_{2}$ diffusion through the bulk of the particle. Finally, $\mathrm{Ca}\left(\mathrm{HCO}_{3}\right)_{2}$ reacts with $\mathrm{Ca}(\mathrm{OH})_{2}$ and forms $\mathrm{CaCO}_{3}$ :

$$
\mathrm{Ca}\left(\mathrm{HCO}_{3}\right)_{2}+\mathrm{Ca}(\mathrm{OH})_{2} \rightarrow 2 \mathrm{CaCO}_{3}+2 \mathrm{H}_{2} \mathrm{O}
$$

Since these carbonation reactions (Eqs. 5 and 7) occur in parallel, the formed solid phase can be considered as a non-protective layer. As the solubility of gases in water is greater at lower temperatures, the carbonation of $\mathrm{Ca}(\mathrm{OH})_{2}$ at a lower temperature is enhanced (Dheilly et al. 2002; Pontiga et al. 2013).

The objective of this work was to investigate the use of natural lime and pelletized lime-cement particles for the direct capture of $\mathrm{CO}_{2}$ from air at ambient conditions, with the sorbents being regenerated via temperature swing. Two particle sizes were considered and experiments were performed in a fixed bed. Using these data, a model was developed to simulate the breakthrough curves and to extract the carbonation kinetics data for various operating conditions. 


\section{Materials and methodology}

\subsection{Materials}

The composition of the natural Cadomin lime, calcined at $850{ }^{\circ} \mathrm{C}$, from X-ray fluorescence (XRF) spectroscopy is presented in Table 1. The pelletized lime particles were made from powdered lime $\left(d_{p}<45 \mu \mathrm{m}\right)$ and calcium aluminate cement $\left(\mathrm{CA}-14, \sim 71 \%\right.$ wt. $\mathrm{Al}_{2} \mathrm{O}_{3}$; $28 \%$ wt. $\mathrm{CaO} ; \sim 1 \%$ wt. impurities). The lime and cement were mixed in a mass ratio of 9:1 in a mechanical pelletizer (Glatt $\mathrm{GmbH})$. Water was then sprayed into the vessel continuously. The resulting pellet size was controlled by the speed of an agitator and chopper attached to the vessel. Table 2 shows some physical properties of the natural and pelletized lime sorbents. The samples with desired particle size range were obtained by sieving. Then, the samples were calcined at $850{ }^{\circ} \mathrm{C}$ in air and their pore surface area was measured by the Brunauer-EmmettTeller (BET) technique with a Micromeritics-TriStar II apparatus. The results presented in Table 2 show that the natural lime particles have a greater bulk density while the pellets have a greater pore surface area, primarily due to the formation of mayenite during calcination (Manovic and Anthony 2009a, b).

\subsection{Methodology}

The schematic of the experimental setup is shown in Fig. 1. A compressor was used to circulate atmospheric air through a water bubbler and then a packed bed of sorbent. The average $\mathrm{CO}_{2}$ concentration of the inlet air, $C_{o}$, was $415 \mathrm{ppm}$ and its relative humidity, as measured by a Vaisala RH-Transmitter, was maintained at $\sim 55 \%$ during all experiments. It should be noted that experiments without the presence of humidified air were also performed to show the effect of humidity for air capture with lime-based sorbents at low temperature. The air stream exiting the bed was sent to an online gas analyzer to determine the residual $\mathrm{CO}_{2}$ content, $C$, of the stream leaving the system.

The column containing the bed of particles is a stainless steel tube with a height of $78.6 \mathrm{~mm}$ and inner diameter of $7.8 \mathrm{~mm}$, as shown in Fig. 2. A uniform bed porosity can be assumed when the column diameter is $10 \times$ to $15 \times$ greater than the mean particle diameter (Akehata and Sato 1985; Gunn 1968; Gunn and Pryce 1969; Stephenson and Stewart 1986). The fixed bed height was set at $68 \mathrm{~mm}$, yielding an aspect ratio of around 8 that will mitigate the impact of entrance effects. Moreover, the column lower section contains glass beads of 200-300 $\mu \mathrm{m}$ in diameter filled to a height of $10 \mathrm{~mm}$ in order to minimize fluid channeling. Finally, a paper

Table 1 Composition of natural lime

\begin{tabular}{lr}
\hline Component & wt $\%$ \\
\hline $\mathrm{CaO}$ & 89.57 \\
$\mathrm{SiO}$ & 4.03 \\
$\mathrm{MgO}$ & 3.92 \\
$\mathrm{Al}_{2} \mathrm{O}_{3}$ & 1.06 \\
$\mathrm{Fe}_{2} \mathrm{O}_{3}$ & 0.51 \\
$\mathrm{~K}_{2} \mathrm{O}$ & 0.38 \\
$\mathrm{Na}_{2} \mathrm{O}$ & 0.35 \\
$\mathrm{SO}_{3}$ & 0.17 \\
$\mathrm{TiO}_{2}, \mathrm{P}_{2} \mathrm{O}_{5}, \mathrm{Br}, \mathrm{Ni}, \mathrm{Mn}, \mathrm{Zn}, \mathrm{Cu}$ & 0.01 \\
Total & 100 \\
\hline
\end{tabular}


Table 2 Physical properties of the sorbents

\begin{tabular}{lllll}
\hline & $\begin{array}{l}\text { Pellets } \\
\left(d_{p}=250-425 \mu \mathrm{m}\right)\end{array}$ & $\begin{array}{l}\text { Pellets } \\
\left(d_{p}=425-600 \mu \mathrm{m}\right)\end{array}$ & $\begin{array}{l}\text { Natural lime } \\
\left(d_{p}=250-425 \mu \mathrm{m}\right)\end{array}$ & $\begin{array}{l}\text { Natural lime } \\
\left(d_{p}=425-600 \mu \mathrm{m}\right)\end{array}$ \\
\hline Bulk density $\left(\mathrm{g} / \mathrm{cm}^{3}\right)$ & 0.87 & 0.84 & 0.98 & 0.96 \\
Surface area $\left(\mathrm{m}^{2} / \mathrm{g}\right)$ & 14.61 & 12.01 & 13.60 & 11.54 \\
\hline
\end{tabular}

filter with pore size of $8 \mu \mathrm{m}$ was also inserted at the bottom of the column. Gas flow rates of 0.5 and $1.0 \mathrm{LPM}$ (at $20^{\circ} \mathrm{C}$ and $1 \mathrm{barg}$ ) were chosen to ensure that the flow regime remained constant in all experiments. The particle Reynolds number varied between 0.37 and 1.12, well below the upper limit value of 10 for laminar flow (Ranade et al. 2011).

Before each experiment, the bed material was pre-hydrated for $3 \mathrm{~h}$ by passing nitrogen through the water bubbler and then the fixed bed. An experiment was typically conducted for only 1 carbonation cycle. For the experiments performed in series of cycles, after each carbonation cycle, sorbents were calcined and prepared for the next cycle. After complete breakthrough, the conversions of sorbent samples from the top, middle, and bottom of the bed were measured by TGA (METTLER TOLEDO-SDTA581) to determine the carbonation profile throughout the bed.

\section{Results and discussion}

\subsection{Importance of system moisture}

The carbonation conversion, $X^{\prime}$, is defined in Eq. 8:

$$
X^{\prime}=\frac{m_{2}-m_{1}}{A \times m_{0}} \times \frac{M_{\mathrm{CaO}}}{M_{\mathrm{CO}_{2}}}
$$

where $m_{2}$ and $m_{1}$ are the mass of carbonated and calcined sample after dehydration, respectively, $m_{0}$ is the initial mass of the calcined sample, $A$ is the fraction of $\mathrm{CaO}$ in the sorbent, and $M_{\mathrm{CaO}}$ and $M_{\mathrm{CO} 2}$ are the molecular weight of calcium oxide and carbon dioxide, respectively.

Figures 3 and 4 show that, although the natural limestone or pelletized limestone particles are pre-hydrated for $3 \mathrm{~h}$, the absence of humidity in the inlet air led to a relatively short breakthrough time (Fig. 3) and the sorbent carbonation was low, at less than $20 \%$ for pelletized limestone and less than $10 \%$ for natural limestone (Figs. 4 a, b). The conditions for all experiments are as given

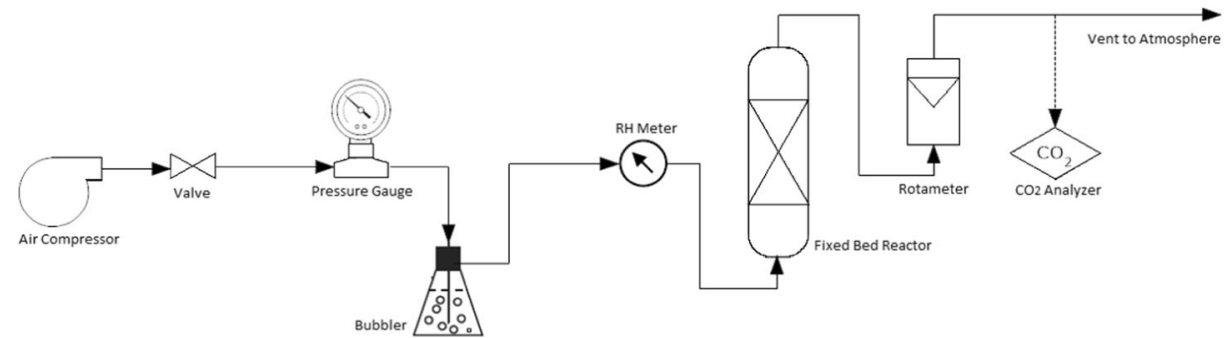

Fig. 1 Experimental setup 
Fig. 2 Fixed bed reactor

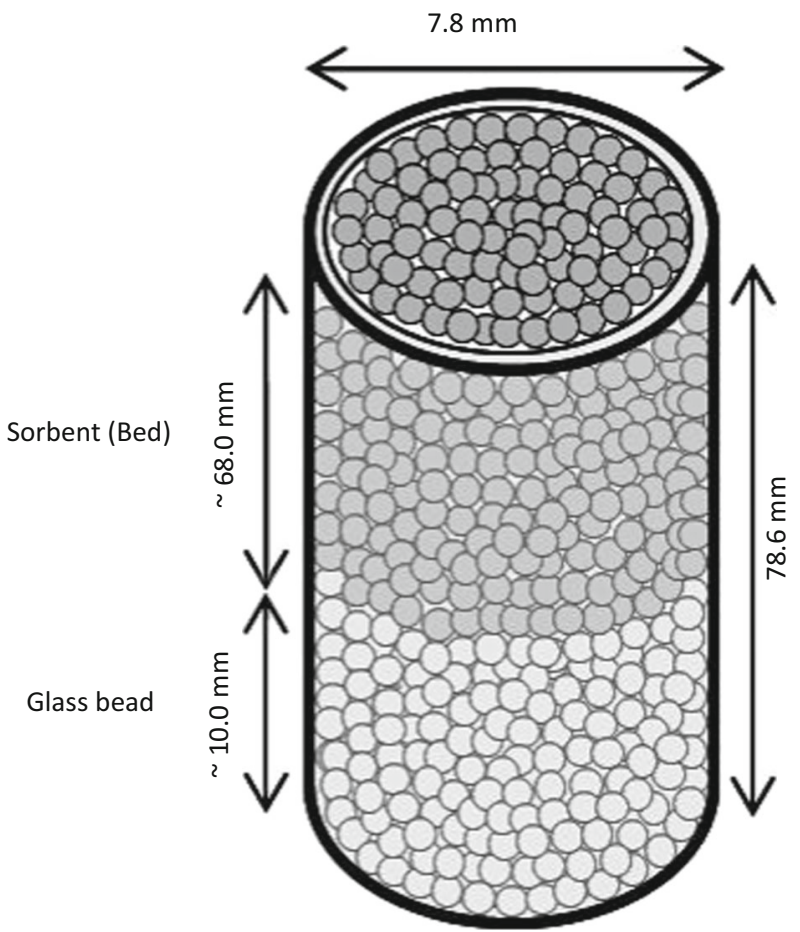

in Fig. 3 unless noted otherwise. These results are in agreement with those in the literature, showing that negligible carbonation occurs when there is insufficient humidity in the reactive system (Beruto and Botter 2000; Dheilly et al. 2002; Nikulshina et al. 2007).

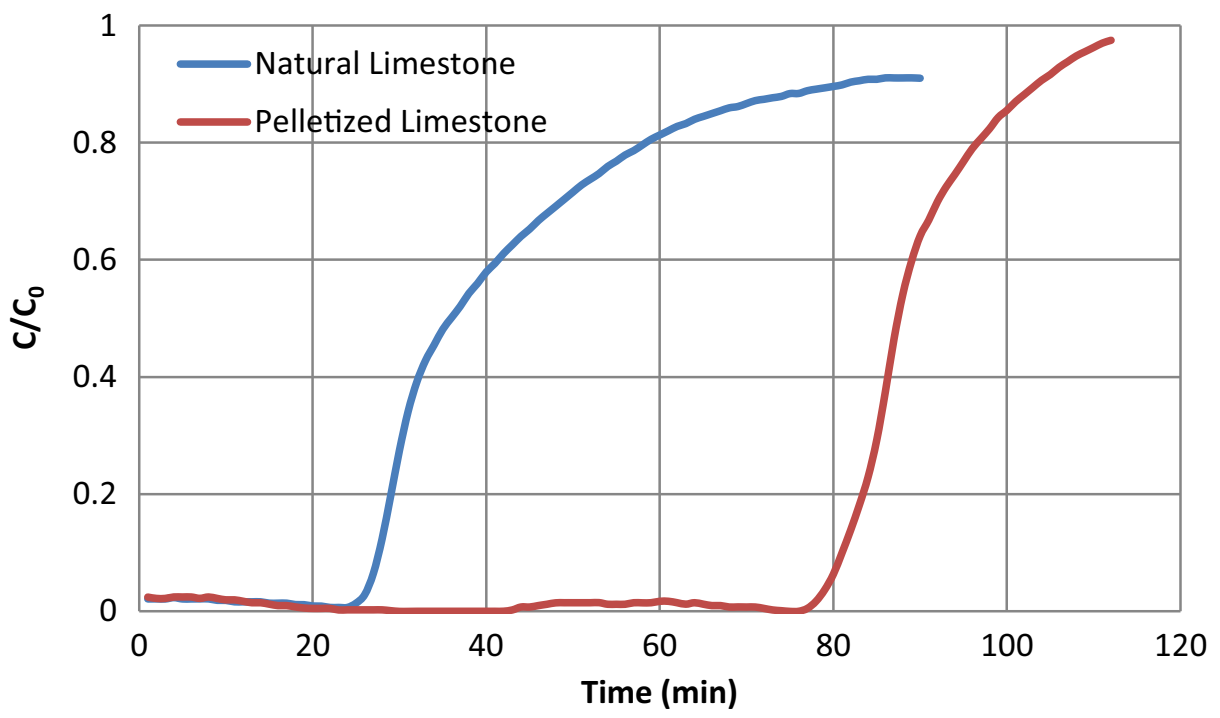

Fig. 3 Breakthrough curves in the absence of humidity in air: pre-hydrated sorbent, $d_{\mathrm{p}}=250-425 \mu \mathrm{m}, Q=$ 1 LPM (1 barg, $20^{\circ} \mathrm{C}$ ) 

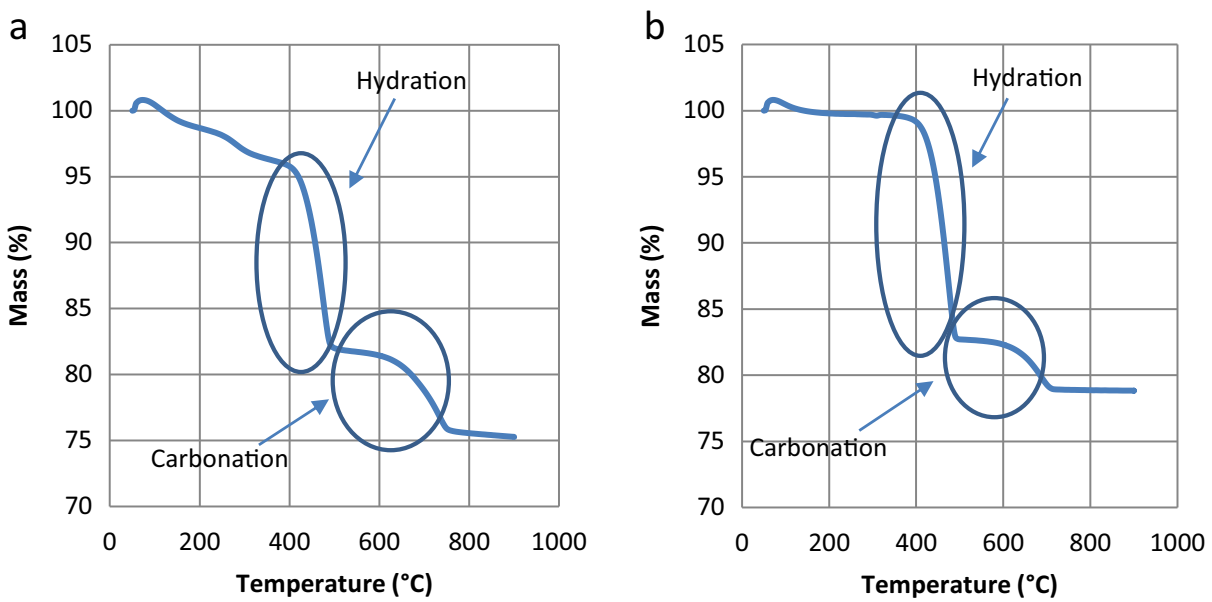

Fig. 4 TGA analysis of post-run sorbents in the absence of humidity in air: pre-hydrated sorbent, $d_{\mathrm{p}}=250$ $425 \mu \mathrm{m}$, dry inlet air, and $Q=1 \operatorname{LPM}\left(1 \mathrm{barg}, 20^{\circ} \mathrm{C}\right)$. a Pelletized limestone. b Natural limestone

On the other hand, if the inlet air is humidified up to 50-55\% relative humidity, but sorbents are not pre-hydrated, an axially non-uniform carbonated bed is observed (Table 3). This phenomenon is due to the partial carbonation of sorbents in the first layers of the bed. While there is competition between $\mathrm{CO}_{2}$ and water to react with $\mathrm{CaO}$, the partial carbonation reaction on the surface of the sorbents prevents further hydration and decreases the reaction rate at the surface. However, in comparison with a dry system where relative humidity was negligible and sorbents were not pre-hydrated, the observed carbonation conversions were more than $50 \%$ higher.

\subsection{Effect of particle size and flow rate}

Figure 5 shows the effect of particle size and gas flow rate on the breakthrough time and breakthrough curve for both the pelletized and natural limestone. As smaller particles have a greater specific surface area $\left(\mathrm{m}^{2} / \mathrm{g}\right)$, it is expected (and observed) that their overall $\mathrm{CO}_{2}$ capture in comparison with larger particles is better. As the slopes of the breakthrough curves are similar for two different gas flow rates, the external mass transfer resistance from bulk to the surface of the particles is, as expected, negligible. The breakthrough time using the pelletized limestone particles was shorter primarily due to the lower content of $\mathrm{CaO}$ as a result of the binder as the total mass loading into the bed was kept constant.

Table 4 presents the carbonation conversion at the top, middle, and bottom of the bed. The axial variation between the lowest and highest values was always less than $8 \%$ points for a given operating condition. This shows that a relatively uniform carbonation conversion along the bed was obtained, confirming the necessity of both moist air and pre-hydration (see axial conversion variation in Table 3 ).

Moreover, a mass balance on $\mathrm{CO}_{2}$ in the gas phase was performed to confirm the sorbent carbonation conversion measured by TGA:

$$
n=C_{0} \times t_{C / C_{0}=0.9} \times \frac{P Q}{R^{\prime} T} \times \eta
$$

where $n$ is the number of $\mathrm{CO}_{2}$ moles that are adsorbed in the bed, $P$ is the pressure of the system, $Q$ is volumetric flow rate, $R$ is the ideal gas constant, $\eta$ is the ratio of the area above the 
Table 3 Hydration and carbonation conversion of non-

Carbonation prehydrated pelletized limestone conversion $(\%)$ with $d_{\mathrm{p}}=250-425 \mu \mathrm{m}$, inlet air at $\mathrm{RH}=55 \%$, and $Q=1 \mathrm{LPM}(1 \mathrm{barg}$, $20{ }^{\circ} \mathrm{C}$ )

\begin{tabular}{ll}
\hline & $\begin{array}{l}\text { Carbonation } \\
\text { conversion (\%) }\end{array}$ \\
\hline Particles from the bottom of the fixed bed & 65.17 \\
Particles from the middle of the fixed bed & 86.96 \\
Particles from the top of the fixed bed & 90.39 \\
\hline
\end{tabular}

breakthrough curve to the total area at time $t$ where $C / C_{0}=0.9$, and $T$ is temperature. To find the surface area above the breakthrough curve, the break point is defined as $C / C_{0}=0.1$ and the end of the breakthrough curve is where $C / C_{0}=0.9$. The difference between estimates was always less than $10 \%$ (average of $5.6 \%$ ).

In the next stage of the experimental program, the pelletized lime and natural lime particles with a diameter range of 425-600 $\mu \mathrm{m}$ were used in a series of nine carbonation/calcination cycles. These cycles consisted of $\mathrm{CO}_{2}$ capture from air at ambient conditions (carbonation) and regeneration of sorbents (calcination) at $850{ }^{\circ} \mathrm{C}$ in air for $75 \mathrm{~min}$. After each carbonation period, the sorbent conversion was measured by TGA and after each calcination period, the sorbent BET surface area was measured. This series of experiments was then repeated for pelletized
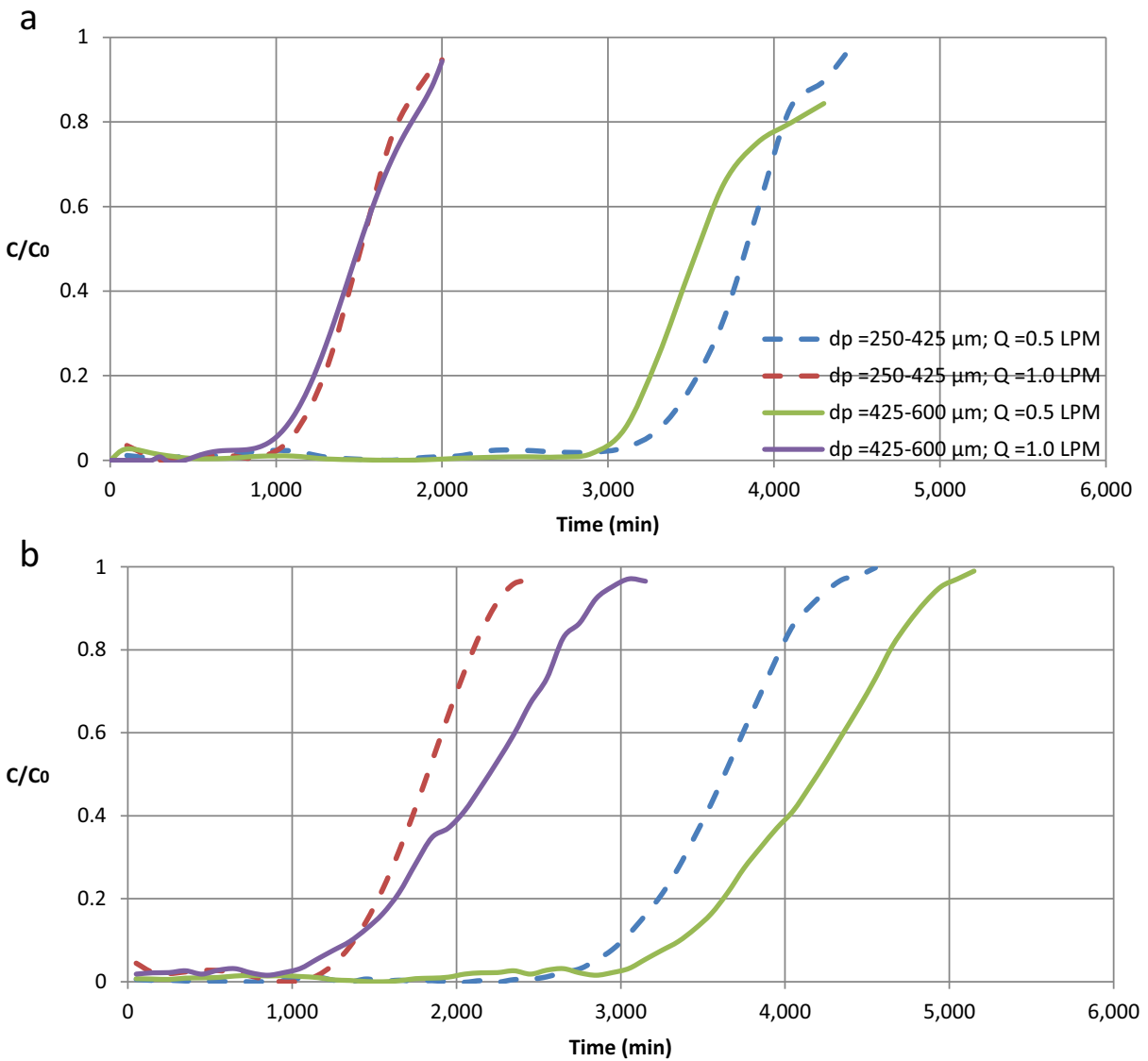

Fig. 5 Impact of particle size and gas flow rate on the breakthrough curve. a Pelletized limestone. b Natural limestone. Flow rates at 1 barg and $20^{\circ} \mathrm{C}$ 
Table 4 Comparison of $\mathrm{CO}_{2}$ conversion: TGA vs. gas mass balance. Flow rates at 1 barg and $20^{\circ} \mathrm{C}$

\begin{tabular}{|c|c|c|c|c|c|c|}
\hline \multirow[t]{2}{*}{ Particle and flow rate } & \multirow{2}{*}{$\begin{array}{l}\text { Conversion } \\
\left(\mathrm{CO}_{2} \text { mass balance }\right) \\
\text { Average }\end{array}$} & \multicolumn{4}{|c|}{ Conversion (TGA) } & \multirow[t]{2}{*}{ Difference $\%$} \\
\hline & & Top & Middle & Bottom & Average & \\
\hline $\begin{array}{l}\text { Pelletized limestone } d_{\mathrm{p}}=250-425 \mu \mathrm{m} \\
O=0.5 \mathrm{~L} / \mathrm{min}\end{array}$ & 0.93 & 0.91 & 0.88 & 0.83 & 0.87 & +6.9 \\
\hline $\begin{array}{l}\text { Pelletized limestone } d_{\mathrm{p}}=250-425 \mu \mathrm{m} \\
Q=1 \mathrm{~L} / \mathrm{min}\end{array}$ & 0.80 & 0.89 & 0.88 & 0.86 & 0.87 & -8.1 \\
\hline $\begin{array}{l}\text { Pelletized limestone } d_{\mathrm{p}}=425-600 \mu \mathrm{m} \\
Q=0.5 \mathrm{~L} / \mathrm{min}\end{array}$ & 0.85 & 0.92 & 0.90 & 0.85 & 0.88 & -3.4 \\
\hline $\begin{array}{l}\text { Pelletized limestone } d_{\mathrm{p}}=425-600 \mu \mathrm{m} \\
Q=1 \mathrm{~L} / \mathrm{min}\end{array}$ & 0.83 & 0.87 & 0.85 & 0.80 & 0.84 & -1.2 \\
\hline $\begin{array}{l}\text { Natural limestone } \\
d_{\mathrm{p}}=250-425 \mu \mathrm{m} \\
Q=0.5 \mathrm{~L} / \mathrm{min}\end{array}$ & 0.89 & 0.92 & 0.90 & 0.90 & 0.91 & -2.2 \\
\hline $\begin{array}{l}\text { Natural limestone } \\
d_{\mathrm{p}}=250-425 \mu \mathrm{m} \\
Q=1 \mathrm{~L} / \mathrm{min}\end{array}$ & 0.80 & 0.91 & 0.93 & 0.84 & 0.89 & -10.1 \\
\hline $\begin{array}{l}\text { Natural limestone } \\
d_{\mathrm{p}}=425-600 \mu \mathrm{m} \\
Q=0.5 \mathrm{~L} / \mathrm{min}\end{array}$ & 0.86 & 0.94 & 0.92 & 0.90 & 0.92 & -6.5 \\
\hline $\begin{array}{l}\text { Natural limestone } \\
d_{\mathrm{p}}=425-600 \mu \mathrm{m} \\
Q=1 \mathrm{~L} / \mathrm{min}\end{array}$ & 0.89 & 0.97 & 0.94 & 0.93 & 0.95 & -6.3 \\
\hline
\end{tabular}

lime at the more realistic calcination conditions of $920^{\circ} \mathrm{C}$ in pure $\mathrm{CO}_{2}$ for $12 \mathrm{~min}$ (representing oxy-fuel combustion), while the rest of the operating conditions remained constant.

\subsection{Performance of sorbents in series of carbonation/calcination cycles}

Table 5 shows the carbonation conversion and BET surface area after selected cycles for pelletized and natural limestone particles. Carbonation conversion of pellets decreased from 80 to $71 \%$ after 9 cycles ( 10 calcinations) due to sintering and loss of porosity during calcination. Although the natural limestone sorbents have an initial carbonation conversion greater than that of the pelletized limestone sorbents, after the same number of cycles, their net decay due to sintering is greater since the pellets have mayenite, which helps better maintain the structural morphology of the particle.

Table 5 Decay of carbonation reaction and surface area for pelletized and natural limestone, $d_{\mathrm{p}}=$ 425-600 $\mu \mathrm{m}$ and $Q=1 \mathrm{LPM}$ (1 barg, $20^{\circ} \mathrm{C}$ )

\begin{tabular}{llll}
\hline Particle & Cycle & $\begin{array}{l}\text { Carbonation } \\
\text { conversion }(\%)\end{array}$ & $\begin{array}{l}\text { Pore surface } \\
\text { area }\left(\mathrm{m}^{2} / \mathrm{g}\right)\end{array}$ \\
\hline Pelletized limestone & 1st & 80 & 12.01 \\
& 2nd & 75 & 10.00 \\
& 4th & 74 & 9.10 \\
& 7th & 71 & 8.30 \\
Natural limestone & 9th & 71 & 7.92 \\
& 1st & 93 & 11.54 \\
& 2nd & 88 & 9.53 \\
& 4th & 81 & 7.69 \\
& 7th & 78 & 6.83 \\
& 9th & 76 & 5.93 \\
\hline
\end{tabular}


Here, carbonation conversions are relatively high due to the mild calcination conditions of air at $850^{\circ} \mathrm{C}$ and for comparison the performance of pelletized limestone calcined for 5 cycles using $\mathrm{CO}_{2}$ at $920{ }^{\circ} \mathrm{C}$ is presented in Table 6 . The higher calcination temperature results in much greater reduction in pore surface area such that the carbonation conversion dropped below $60 \%$ after 5 carbonation cycles.

\subsection{Modeling carbonation kinetics}

Previous investigations on DAC via lime-based sorbents (Beruto and Botter 2000; Dheilly et al. 2002; Nikulshina et al. 2007) used small particles that did not present significant transport limitations. This study explores performance of larger particles $(250-425 \mu \mathrm{m}$ and $425-$ $600 \mu \mathrm{m})$ that are suitable for use in fixed or fluidized beds. Hence, fitting the breakthrough curves from this study with the previously developed surface reaction rate-limiting models is not suitable since diffusional resistance plays a more pronounced role. For non-catalytic gassolid reactions, the unreacted shrinking core model is one of the simplest models as it does not require structural parameters of the reacting solid. Usually, three major steps are considered in such models:

- Diffusion of the gaseous reactant $\left(\mathrm{CO}_{2}\right)$ through the gaseous film surrounding the particle to the particle surface; not a rate-limiting step in the present setup.

- Diffusion of the gaseous reactant through the product layer to the unreacted core; characterized by the effective diffusivity, $D_{\mathrm{e}}$.

- Reaction of the gaseous reactant with the solid at the unreacted core surface; characterized by $K_{\mathrm{s}}$, the surface reaction rate constant.

In this research, the model accounts for reactions given in Eqs. 1-7. Moreover, as explained above, the formation of the $\mathrm{Ca}\left(\mathrm{HCO}_{3}\right)_{2}$ on the product layer enhances the diffusion of $\mathrm{CO}_{2}$ to the bulk of the particle. However, continued formation of $\mathrm{CaCO}_{3}$ impedes further $\mathrm{CO}_{2}$ diffusion. The model predicts the time required to reach a given conversion, based on the following equations, as detailed by Levenspiel (1972):

$$
\begin{aligned}
& \mathrm{aA}_{(\mathrm{g})}+\mathrm{bB}_{(\mathrm{s})} \rightarrow \text { solid product for a particle of unchanging size } \\
& \qquad \mathrm{t} / \mathrm{T}_{\mathrm{MT}}=\mathrm{X}_{\mathrm{B}} \\
& \text { and } \mathrm{T}_{\mathrm{MT}}=\frac{\rho_{\mathrm{B}} \mathrm{R}}{3 \mathrm{~b} \mathrm{~K}_{\mathrm{g}} \mathrm{C}_{\mathrm{Ag}}}
\end{aligned}
$$

Table 6 Performance of pelletized limestone after 4 cycles of carbonation and calcination, $d_{\mathrm{p}}=425-600 \mu \mathrm{m}$ and $Q=1 \mathrm{LPM}\left(1 \mathrm{barg}, 20^{\circ} \mathrm{C}\right)$

\begin{tabular}{lllll} 
& $\begin{array}{l}\text { Initial pore } \\
\text { surface area }\end{array}$ & $\begin{array}{l}\text { Pore surface area } \\
\text { after } 5 \text { calcinations }\left(\mathrm{m}^{2} / \mathrm{g}\right)\end{array}$ & $\begin{array}{l}\text { Carbonation } \\
\text { conversion } \\
(1 \mathrm{st} \text { cycle })(\%)\end{array}$ & $\begin{array}{l}\text { Carbonation } \\
\text { conversion } \\
(5 \text { th cycle })(\%)\end{array}$ \\
\hline Calcination with pure $\mathrm{CO}_{2}$ at $920^{\circ} \mathrm{C}$ & 12.01 & 3.20 & 81 & 59 \\
Calcination with air at $8500^{\circ} \mathrm{C}$ & & 9.10 & 80 & 74 \\
\hline
\end{tabular}




$$
\begin{gathered}
t / T_{D P}=1-3\left(1-X_{B}\right)^{2 / 3}+2\left(1-X_{B}\right) \\
\text { and } T_{D P}=\frac{\rho_{B} R^{2}}{6 b D_{e} C_{A g}} \\
t / T_{R, S C}=1-\left(1-X_{B}\right)^{1 / 3} \\
\text { and } T_{R, S C}=\frac{\rho_{B} R}{b K_{S} C_{A g}}
\end{gathered}
$$

where $\mathrm{DB}, \mathrm{MT}$, and $\mathrm{R}, \mathrm{SC}$ are the characteristic times for diffusion of the gaseous reactant through the product layer of the particles, external mass transfer from the bulk gas to the surface of the particle, and chemical reaction at the interface between the unreacted core of the pellet and the product layer, respectively, and $X_{\mathrm{B}}$ is conversion, calculated as:

$$
X_{\mathrm{B}}=1-\left(\frac{r_{\mathrm{c}}}{R}\right)^{3}
$$

To find the relationship between $C_{0}$ and $X_{\mathrm{B}}$ at any point on the breakthrough curve, a mass balance on a differential axial cross-section element of the bed based on the method proposed by Fenouil and Lynn (1996) was used:

$$
\frac{C}{C_{\mathrm{o}}}=\frac{X_{\mathrm{B}}-\frac{u_{\mathrm{t}} \varepsilon_{\mathrm{fb}}}{u_{\mathrm{g}}}}{1-\frac{u_{\mathrm{t}} \varepsilon_{\mathrm{fb}}}{u_{\mathrm{g}}}}
$$

where $u_{\mathrm{t}}$ is the moving velocity of the transition zone, calculated by an overall $\mathrm{CO}_{2}$ mass balance over the bed:

$$
u_{\mathrm{t}}=\frac{u_{\mathrm{g}} C_{\mathrm{o}}}{\left(1-\varepsilon_{\mathrm{fb}}\right) C_{\mathrm{Ca}(\mathrm{OH}) 2}}
$$

Initially, there is no protective layer $\left(\mathrm{CaCO}_{3}\right)$ and carbonation rate is controlled by the kinetics of the chemical reaction. After the formation of the product layer $\left(\mathrm{CaCO}_{3}\right)$, diffusion through this layer becomes the $\mathrm{CO}_{2}$ capture controlling step. Results from fitting the data presented in Fig. 5 are summarized in Table 7. Figures 6 and 7 compare experimental data and model predictions for conversion $\left(X_{\mathrm{B}}\right.$ in Eqs. 14 and 15). As it can be seen, although there are slight variations, the agreement between model and experimental measurements is generally very good.

From Fig. 5, it can be seen that the impact of gas flow rate was marginal in terms of affecting the shape of the breakthrough curve. The mass transfer resistance from the bulk gas to the surface of the particles was thus assumed in the model to be negligible, which was validated by the fact that the gas flow rate does not affect the fitting model parameters, $K_{\mathrm{s}}$ and $D_{\mathrm{e}}$. For the pelletized limestone particles, the average effective diffusivity is $6.30 \times 10^{-7}$ and $5.38 \times 10^{-7} \mathrm{~m}^{2} / \mathrm{s}$ for particle diameters of $250-425 \mu \mathrm{m}$ and $425-600 \mu \mathrm{m}$, respectively, whereas the surface reaction rate constant is similar for all conditions with an average value of $2.36 \times$ $10^{-3} \mathrm{~m} / \mathrm{s}$. Effective diffusivity for smaller particles is higher than for larger particles, while the surface reaction rate constant is similar for both particle ranges. 
Table 7 Reaction rate constant and effective diffusivity constant of pelletized and natural limestone

\begin{tabular}{|c|c|c|c|c|c|}
\hline Particle & Model parameter & $\begin{array}{l}d_{\mathrm{p}}=250- \\
425 \mu \mathrm{m} \\
Q=0.5 \mathrm{~L} / \mathrm{min}\end{array}$ & $\begin{array}{l}d_{\mathrm{p}}=250-425 \mu \mathrm{m} \\
Q=1 \mathrm{~L} / \mathrm{min}\end{array}$ & $\begin{array}{l}d_{\mathrm{p}}=425-600 \mu \mathrm{m} \\
Q=0.5 \mathrm{~L} / \mathrm{min}\end{array}$ & $\begin{array}{l}d_{\mathrm{p}}=425-600 \mu \mathrm{m} \\
Q=1 \mathrm{~L} / \mathrm{min}\end{array}$ \\
\hline \multirow[t]{2}{*}{$\begin{array}{l}\text { Pelletized } \\
\text { limestone }\end{array}$} & $\begin{array}{l}\text { Diffusion controlled } \\
D_{\mathrm{e}}\left(\mathrm{m}^{2} / \mathrm{s}\right)\end{array}$ & $6.44 \times 10^{-7}$ & $6.16 \times 10^{-7}$ & $5.24 \times 10^{-7}$ & $5.51 \times 10^{-7}$ \\
\hline & $\begin{array}{l}\text { Reaction controlled } \\
K_{\mathrm{s}}(\mathrm{m} / \mathrm{s})\end{array}$ & $1.88 \times 10^{-3}$ & $2.39 \times 10^{-3}$ & $2.29 \times 10^{-3}$ & $2.86 \times 10^{-3}$ \\
\hline \multirow[t]{2}{*}{$\begin{array}{l}\text { Natural } \\
\text { limestone }\end{array}$} & $\begin{array}{l}\text { Diffusion controlled } \\
D_{\mathrm{e}}\left(\mathrm{m}^{2} / \mathrm{s}\right)\end{array}$ & $4.90 \times 10^{-7}$ & $4.93 \times 10^{-7}$ & $8.01 \times 10^{-8}$ & $8.80 \times 10^{-8}$ \\
\hline & $\begin{array}{l}\text { Reaction controlled } \\
K_{\mathrm{s}}(\mathrm{m} / \mathrm{s})\end{array}$ & $1.80 \times 10^{-3}$ & $2.69 \times 10^{-3}$ & $2.00 \times 10^{-3}$ & $2.26 \times 10^{-3}$ \\
\hline
\end{tabular}

Similar results are obtained with the natural limestone particles where smaller particles had a greater effective diffusivity and the surface reaction constant is similar for all conditions as well
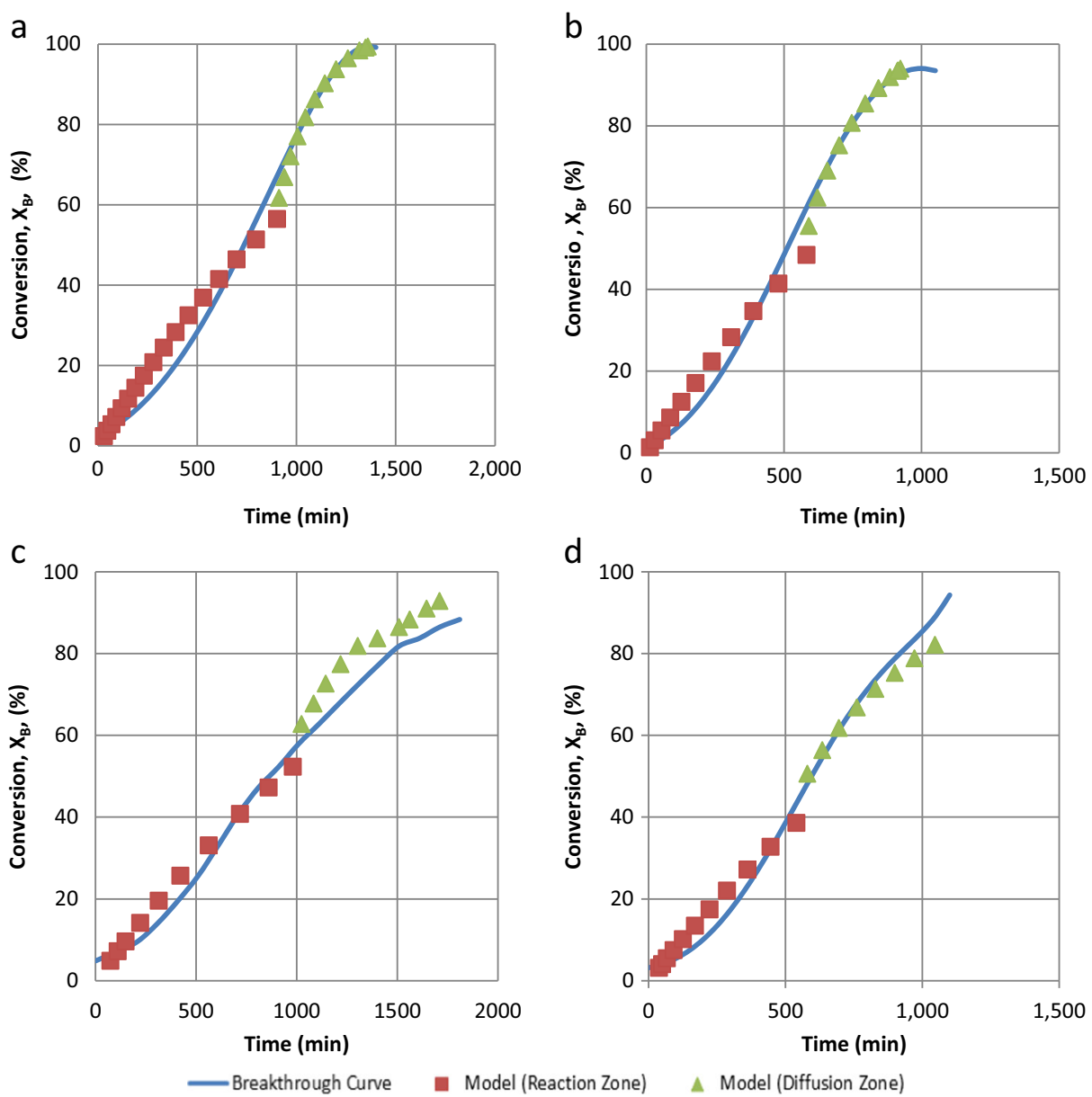

Fig. 6 Modeling of the breakthrough curves of pelletized limestone. a $d_{\mathrm{p}}=250-425 \mu \mathrm{m}$ and $Q=0.5 \mathrm{~L} / \mathrm{min}$. b $d_{\mathrm{p}}=250-425 \mu \mathrm{m}$ and $Q=1.0 \mathrm{~L} / \mathrm{min} . \mathbf{c} d_{\mathrm{p}}=425-600 \mu \mathrm{m}$ and $Q=0.5 \mathrm{~L} / \mathrm{min} . \mathbf{d} d_{\mathrm{p}}=425-600 \mu \mathrm{m}$ and $Q=1.0 \mathrm{~L} /$ min. Flow rates at 1 barg and $20^{\circ} \mathrm{C}$ 

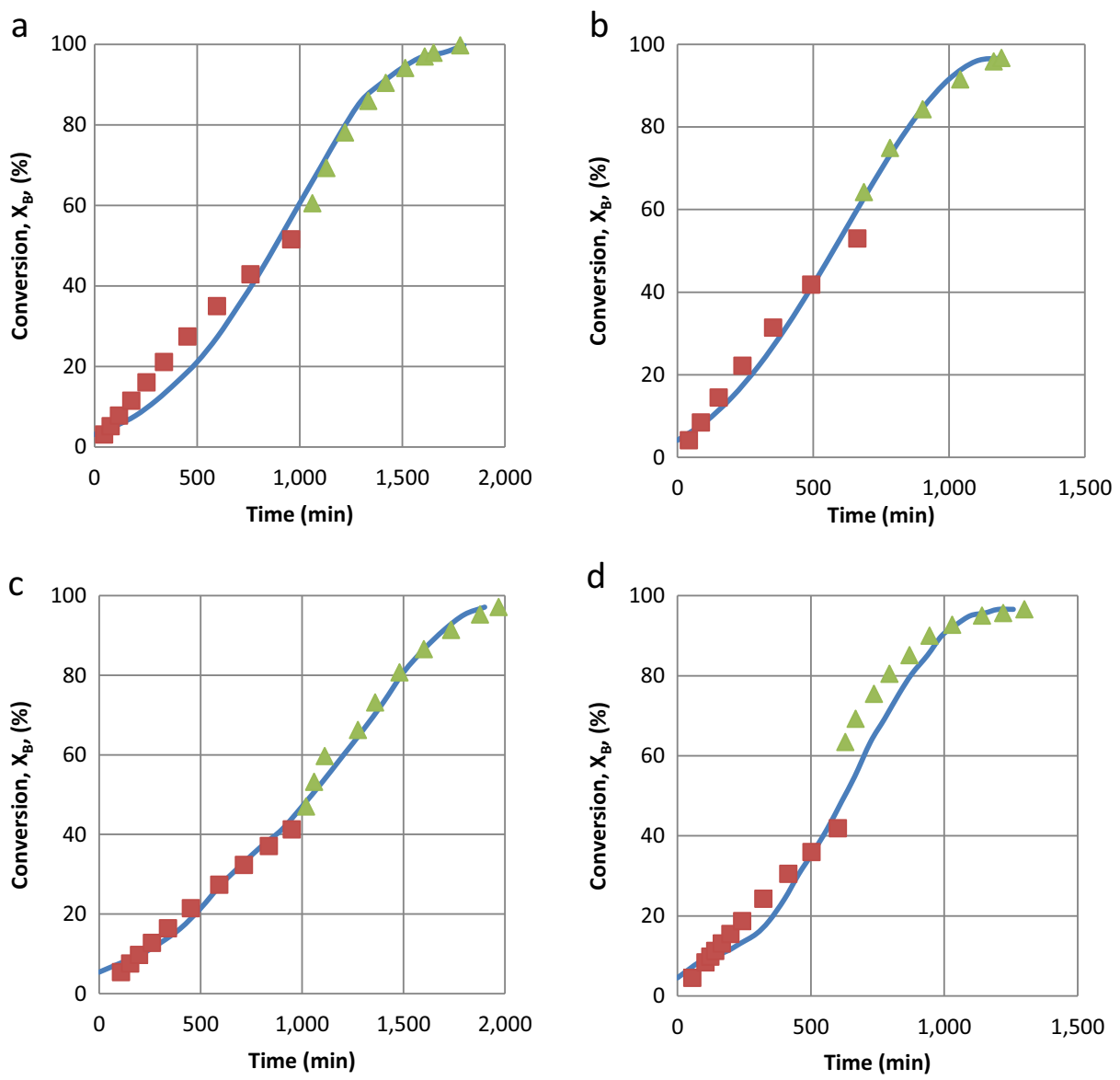

Breakthrough Curve

Model (Reaction Zone)

A. Model (Diffusion Zone)

Fig. 7 Modeling of the breakthrough curve of natural limestone. a $d_{\mathrm{p}}=250-425 \mu \mathrm{m}$ and $Q=0.5 \mathrm{~L} / \mathrm{min}$. $\mathbf{b} d_{\mathrm{p}}=$ $250-425 \mu \mathrm{m}$ and $Q=1.0 \mathrm{~L} / \mathrm{min}$. $\mathbf{c} d_{\mathrm{p}}=425-600 \mu \mathrm{m}$ and $Q=0.5 \mathrm{~L} / \mathrm{min}$. d $d_{\mathrm{p}}=425-600 \mu \mathrm{m}$ and $Q=1.0 \mathrm{~L} / \mathrm{min}$. Flow rates at 1 barg and $20^{\circ} \mathrm{C}$

as for the average value obtained for the pelletized limestone. However, effective diffusivity of pelletized limestone is greater than for natural limestone. For instance, the average value of $D_{\mathrm{e}}$ is $5.38 \times 10^{-7} \mathrm{~m}^{2} / \mathrm{s}$ for pelletized limestone with a particle diameter range of $425-600 \mu \mathrm{m}$, while its average value is $8.41 \times 10^{-8} \mathrm{~m}^{2} / \mathrm{s}$ for natural limestone with the same particle size. Similarly, for the particle diameter range of $250-425 \mu \mathrm{m}$, the average value of $D_{\mathrm{e}}$ is $6.30 \times 10^{-7} \mathrm{~m}^{2} / \mathrm{s}$ and $4.91 \times 10^{-7} \mathrm{~m}^{2} / \mathrm{s}$ for the pelletized and natural limestone, respectively. This arises because the binder increases the pore surface area of the sorbent.

\section{Conclusions}

The performance of the natural limestone from Cadomin and the pelletized limestone $(90 \%$ natural limestone and $10 \%$ calcium aluminate cement (CA-14)) was compared as sorbent for direct $\mathrm{CO}_{2}$ capture from air at ambient conditions in a fixed bed reactor. Results show that pre- 
hydration of the sorbents leads to a uniformly carbonated bed. Moreover, relative humidity is an important parameter on the carbonation of sorbents. In a dry system, the breakthrough time was very short and the carbonation conversion of the sorbents was low in comparison with a system with $55 \%$ relative humidity.

Comparing the performance of two sorbents in series of 9 carbonation/calcination cycles at $850^{\circ} \mathrm{C}$ under air shows that, due to the presence of the binder in pelletized limestone sorbents, their net decay in carbonation conversion (from 80 to $71 \%$ ) was less than for natural limestone (from 93 to $76 \%$ ). Moreover, the decay in pore surface area (from 12.01 to $7.92 \mathrm{~m}^{2} / \mathrm{g}$ ) compared with that of natural limestone (from 11.54 to $5.93 \mathrm{~m}^{2} / \mathrm{g}$ ) shows that pelletized limestone does not sinter as much as natural limestone. Hence, pelletized limestone sorbents were chosen for further study under simulated oxy-fuel calcination conditions $\left(920^{\circ} \mathrm{C}\right.$ in pure $\left.\mathrm{CO}_{2}\right)$. However, their carbonation conversion fell (from 81 to $59 \%$ ) and pore surface area drastically decreased (from 12.01 to $3.20 \mathrm{~m}^{2} / \mathrm{g}$ ) after 5 cycles. The presented results on sorbent performance are promising and show that DAC employing lime-based sorbents can be considered as a feasible strategy to mitigate climate change taking $\mathrm{CO}_{2}$ directly from the atmosphere.

The shrinking core model was used for mathematical modeling of breakthrough curve data. Based on preliminary observations, changing the flow rate does not have an effect on the overall kinetics of the reaction. Hence, the mass transfer resistance from bulk gas to the particle surface was assumed negligible. The carbonation of sorbents can be divided into two regimes: reaction-controlled and diffusion-controlled. Initially, the carbonation rate is controlled by the chemical reaction kinetics on the surface of the particle. As the reaction proceeds, the formation of the product layer on the surface of the particles moves the reaction into a diffusion-controlled regime. Results from mathematical modeling also confirm these hypotheses. Changing the flow rate does not affect the fitting values of effective diffusivity or the surface reaction constant of the sorbents. Furthermore, the surface reaction constant of smaller particles is similar to that of larger particles, while their effective diffusivity was greater. The average effective diffusivity, as expected, was greater for pelletized limestone than for natural limestone. This can be attributed to their higher porosity. Therefore, the main difference between the pelletized limestone and natural limestone in $\mathrm{CO}_{2}$ capture at ambient conditions arises from the higher effective diffusivity of pelletized limestone.

\section{Nomenclature}

A Calcium oxide fraction in the particle (-)

$C_{0} \quad \mathrm{CO}_{2}$ concentration in inlet air ( $\left.\mathrm{ppm}\right)$

$C \quad \mathrm{CO}_{2}$ concentration (ppm)

$C_{\mathrm{Ag}}$ Inlet gas concentration $\left(\mathrm{kg} / \mathrm{m}^{3}\right)$

$d_{\mathrm{p}}$ Particle diameter $(\mathrm{m})$

$D$ Column diameter (m)

$D_{\text {e }}$ Effective diffusivity $\left(\mathrm{m}^{2} / \mathrm{s}\right)$

$k$ Boltzmann constant $(\mathrm{J} / \mathrm{K})$

$K_{\mathrm{s}} \quad$ Surface reaction constant $(\mathrm{m} / \mathrm{s})$

$K_{\mathrm{g}}$ External mass transfer coefficient $(\mathrm{m} / \mathrm{s})$

$m$ Mass (g)

$n \quad$ Number of moles (mol) 


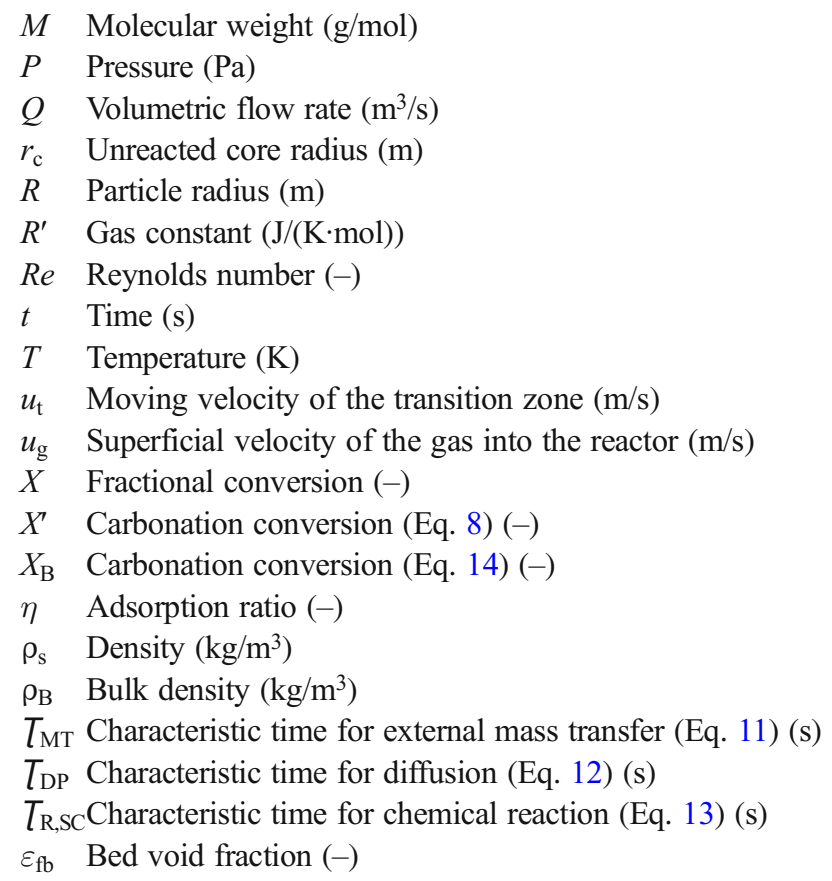

Funding information The authors would like to thank CanmetENERGY (Natural Resources Canada), the Natural Sciences and Engineering Research Council of Canada, and the Carbon Management Canada for their financial support for this research.

Open Access This article is distributed under the terms of the Creative Commons Attribution 4.0 International License (http://creativecommons.org/licenses/by/4.0/), which permits unrestricted use, distribution, and reproduction in any medium, provided you give appropriate credit to the original author(s) and the source, provide a link to the Creative Commons license, and indicate if changes were made.

Publisher's note Springer Nature remains neutral with regard to jurisdictional claims in published maps and institutional affiliations.

\section{References}

Akehata T, Sato K (1985) Flow distribution in packed beds. J Chem Eng Japan 27:430-436

Astarita G, Savage DW, Bisio A (1993) Gas treating with chemical solvents. Wiley, New York

Beruto DT, Botter R (2000) Liquid like $\mathrm{H}_{2} \mathrm{O}$ adsorption layers to catalyze the $\mathrm{Ca}(\mathrm{OH})_{2} / \mathrm{CO}_{2}$ solid-gas reaction and to form a non-protective solid product layer at $20{ }^{\circ} \mathrm{C}$. J Eur Ceram Soc 20:497-503

Bottoms RR (1930) U.S. Patent No. 1,783,901

Carbon Engineering (2019) Direct air capture. http://carbonengineeringcom/about-dac/. Accessed 15 Jan 2019

Choi S, Drese JH, Eisenberger PM, Jones CW (2011) Application of amine-tethered solid sorbents for $\operatorname{direct} \mathrm{CO}_{2}$ capture from the ambient air. Environ Sci Technol 45:2420-2427

Dheilly RM, Tudo J, Sebaïbi Y, Quéneudec M (2002) Influence of storage conditions on the carbonation of powdered $\mathrm{Ca}(\mathrm{OH})_{2}$. Constr Build Mater 16:155-161

Erans M, Jeremias M, Zheng L, Yao JG, Blamey J, Manovic V, Fennell PS, Anthony EJ (2018) Pilot testing of enhanced sorbents for calcium looping with cement production. Appl Energy 225:392-401

Fenouil LA, Lynn S (1996) Design of entrained-flow and moving, packed, and fluidized-bed sorption systems: grain-model kinetics for hot coal-gas sulfurization with limestone. Ind Eng Chem Res 35:1024-1043

Gunn DJ (1968) Mixing in packed and fluidized beds. Chem Eng J CE153-172 
Gunn DJ, Pryce C (1969) Dispersion in packed beds. Trans IChemE 47:T341-T350

International Energy Agency (IEA) (2011) $\mathrm{CO}_{2}$ emissions from fuel combustion

International Energy Agency (IEA) (2013) $\mathrm{CO}_{2}$ emissions from fuel combustion

International Panel on Climate Change (IPCC) (2007) Fourth assessment report of the Intergovernmental Panel on Climate Change "climate change 2007 - the physical science basis"

Kalinkin AM, Kalinkina EV, Zalkind OA, Makarova TI (2005) Chemical interaction of calcium oxide and calcium hydroxide with $\mathrm{CO}_{2}$ during mechanical activation. Inorg Mater 41:1073-1079

Keith DW, Ha-Duong M, Stolaroff JK (2006) Climate strategy with $\mathrm{CO}_{2}$ capture from the air. Climate Change 7474:17-45

Levenspiel O. (1972) Chemical reaction engineering, 2nd ed, chapter 13, pp 357-371

Lüthi D, Floch ML, Bereiter B, Blunier T, Barnola JM, Siegenthaler U, Raynaud D, Jouzel J, Fischer H, Kawamura K, Stocker TF (2008) High-resolution carbon dioxide concentration record 650,000-800,000 years before present. Nature 453:379-382

Mahmoudkhani M, Keith DW (2009) Low energy sodium hydroxide recovery for $\mathrm{CO}_{2}$ capture from atmospheric air - thermodynamic analysis. Int J Greenh Gas Contr 3:376-384

Mahmoudkhani M, Heidel KR, Ferreira JC, Keith DW, Cherry RS (2009) Low energy packed tower and caustic recovery for direct capture of $\mathrm{CO}_{2}$ from air. Energy Procedia 1:1535-1542

Manovic V, Anthony EJ (2009a) CaO-based pellets supported by calcium aluminate cements for hightemperature $\mathrm{CO}_{2}$ capture. Environ Sci Technol 43:7117-7122

Manovic V, Anthony EJ (2009b) Long-term behavior of CaO-based pellets supported by calcium aluminate cements in a long series of $\mathrm{CO}_{2}$ capture cycles. Ind Eng Chem Res 48:8906-8912

Manovic V, Anthony EJ (2010) $\mathrm{CO}_{2}$ carrying behavior of calcium aluminate pellets under high temperature/high$\mathrm{CO}_{2}$ concentration calcination conditions. Ind Eng Chem Res 49:6916-6922

Manovic V, Wu Y, He I, Anthony EJ (2012) Spray water reactivation pelletization of spent CaO-based sorbents from calcium looping cycles. Environ Sci Technol 46:12720-12725

Nakicenovic N. et al. (2000) Emissions scenarios. A special report of working group III of the IPCC, Cambridge University Press: pp. 599

Nikulshina V, Hirsch D, Mazzotti M, Steinfield A (2006) $\mathrm{CO}_{2}$ capture from air and co-production of $\mathrm{H}_{2}$ via the $\mathrm{Ca}(\mathrm{OH})_{2}-\mathrm{CaCO}_{3}$ cycle using concentrated solar power - thermodynamic analysis. Energy 31:1379-1389

Nikulshina V, Gavez ME, Steinfeld A (2007) Kinetic analysis of the carbonation reactions for the capture of $\mathrm{CO}_{2}$ from air via the $\mathrm{Ca}(\mathrm{OH})_{2}-\mathrm{CaCO}_{3}-\mathrm{CaO}$ solar thermochemical cycle. Chem Eng J 129:75-83

Petit JR, Jouzel J, Raynaud D, Barkov NI, Barnola JM, Basile I, Bender M, Chappellaz J, Davis M, Delaygue G, Delmotte M, Kotlyakov VM, Legrand M, Lipenkov VY, Lorius C, Pepin L, Ritz C, Saltzman E, Stievenard M (1999) Climate and atmospheric history of the past 420,000 years from the Vostok ice core, Antarctica. Nature 399:429-436

Pontiga F, Valverde JM, Moreno H, Duran-Olivencia FJ (2013) Dry gas-solid carbonation in fluidized beds of $\mathrm{Ca}(\mathrm{OH})_{2}$ and nanosilica/Ca(OH) 2 at ambient temperature and low $\mathrm{CO}_{2}$ pressure. Chem Eng $\mathrm{J} 222546-552$

Ranade VV, Chaudhari R, Gunjal PR (2011) Trickle bed reactors: reactor engineering \& applications, chapter 4

Ranjan M, Herzog HJ (2011) Feasibility of air capture. Energy Procedia 4:2869-2876

Sculley JP, Zhou HC (2012) Enhancing amine-supported materials for ambient air capture. Angewandte Chemie International Edition 12660-12661

Stephenson JL, Stewart WE (1986) Optical measurement of porosity and fluid motion in packed beds. Chem Eng Sci 42:2161-2170

Tian S, Jiang J, Zhang Z, Manovic V (2018) Inherent potential of steelmaking to contribute to decarbonisation targets via industrial carbon capture and storage. Nat Commun 9:1-8

Yang RY, Zou RP, Yu AB (2003) Effect of material properties on the packing of fine particles. J Appl Phys 94: 3025-3034

Zheng L, Hills TP, Fennell P (2016) Phase evolution, characterisation, and performance of cement prepared in an oxy-fuel atmosphere. Faraday Discuss 192:113-124 